\title{
Amyloidosis and Neurodegenerative Diseases: Current Treatments and New Pharmacological Options
}

\author{
Jean-Paul Tillement ${ }^{\mathrm{a}} \quad$ Laurent Lecanu $^{\mathrm{b}, \mathrm{c}}$ Vassilios Papadopoulos ${ }^{\mathrm{a}-\mathrm{e}}$ \\ ${ }^{a}$ Académie Nationale de Médecine Paris, Paris, France; ${ }^{b}$ Research Institute, McGill University Health Centre, \\ and Departments of ${ }^{\mathrm{C}}$ Medicine, ${ }^{\mathrm{d}}$ Pharmacology and Therapeutics and ${ }^{\mathrm{e} B i o c h e m i s t r y}$, McGill University, \\ Montreal, Que., Canada
}

\section{Key Words}

Alzheimer's disease $\cdot$ Parkinson's disease $\cdot$ Huntington's disease $\cdot$ Spinocerebellar ataxia $\cdot$ Multiple systemic atrophy Niemann-Pick disease $\cdot$ Progressive supranuclear palsy · Amyotrophic lateral sclerosis · Prions - Amyloid proteins • Cholesterol $\cdot$ Mitochondria

\begin{abstract}
Most neurodegenerative diseases share several clinical, genetic and pathophysiological features, and an irreversible evolution as well. They are characterized by an endogenous production of abnormal proteins called amyloid proteins (AP), which are not hydrosoluble, form depots, and are only partly cleared by autophagy and the ubiquitin-protease system. Despite their different structures, they are probably generated by a common pathological pathway, a misfolding process. This hypothesis suggests a common pharmacological approach, which can consist of either the blockade of the misfolding process, the elimination of AP or both. The currently validated treatments are mostly palliative ones, trying to supplant the function of destroyed neurons. New trends involve the regulation of the cerebral cholesterol metabolism and the preservation of neuron mitochondrial functions. Special attention is given to already marketed drugs used for other indications, which are also able to act on neurodegeneration.

Copyright $\odot 2009$ S. Karger AG, Basel
\end{abstract}

\section{Introduction}

Neurodegenerative diseases are numerous and vary a great deal in frequency and phenotype. Alzheimer's disease (AD), and the senile dementias that are now semiologically associated with it, and Parkinson's disease (PD), either with or without associated dementia, have the highest prevalence, most likely due to increased life span. Other diseases such as amyotrophic lateral sclerosis (ALS) occur less frequently and their incidence is relatively stable; others still, such as Huntington's disease (HD), are rare.

The classification of these diseases was first based on common clinical criteria, notably mental deterioration coupled with cognitive impairment, memory loss and the deterioration of motor function characterized by abnormal movement or palsy, which varies depending on the disease. These diseases also share a common, always irreversible and often fatal progression. It has also been observed that they could be transmitted genetically, at least in certain kindred. This general rule applies for HD; however, for other diseases such as $\mathrm{AD}$, genetic transmission is responsible for only a small percentage of patients (5\%). The large majority of patients (95\%) have no identified family history, meaning the disease is sporadic and acquired [1]. These diseases have different timings of onset depending on their genetic or nongenetic origin. Cas-

\section{KARGER}

Fax +41613061234 E-Mail karger@karger.ch www.karger.com
(C) 2009 S. Karger AG, Basel

0031-7012/10/0851-0001\$26.00/0

Accessible online at:

www.karger.com/pha
Vassilios Papadopoulos

Research Institute, McGill University Health Centre

1650 Cedar Avenue, C10-148, Montreal, QC H3G 1A4 (Canada)

Tel. +1 514934 1934, ext. 44580, Fax +1 5149348439

E-Mail vassilios.papadopoulos@ mcgill.ca 
Table 1. The main AP and their corresponding diseases, locations, mutated genes and risk

\begin{tabular}{|c|c|c|c|c|}
\hline \multirow[t]{2}{*}{ AP } & \multirow[t]{2}{*}{ Disease } & \multicolumn{2}{|l|}{ Cellular location } & \multirow[t]{2}{*}{ Risk factor } \\
\hline & & intra & extra & \\
\hline $\begin{array}{l}\beta \text {-Amyloid } \\
A \beta_{1-40} \text { and } A \beta_{1-42}\end{array}$ & $\mathrm{AD}$ & & plaque & ApoE4 \\
\hline Hyperphosphorylated tau & $\begin{array}{l}\text { AD } \\
\text { FTDP-17 } \\
\text { Niemann-Pick disease } \\
\text { progressive supranuclear palsy } \\
\text { ALS }\end{array}$ & $\begin{array}{l}\text { neuron, oligodendrocytes, } \\
\text { astrocytes, cytoplasm }\end{array}$ & & MAPT haplotype \\
\hline$\alpha$-Synuclein & $\begin{array}{l}\text { multiple systemic atrophy } \\
\text { Lewy body dementia } \\
\text { PD }\end{array}$ & $\begin{array}{l}\text { neuron, oligodendrocytes, } \\
\text { cytoplasm }\end{array}$ & & $\begin{array}{l}\text { SNCA polymorphism } \\
M A P T \text { haplotype }\end{array}$ \\
\hline Ataxin & spinocerebellar ataxia & neuron, nucleus & & \\
\hline Huntingtin & $\mathrm{HD}$ & neuron, nucleus & & \\
\hline Prion protein-resistant protease & Prion & & plaque & PRNP polymorphism \\
\hline SOD1 & ALS & neuron, cytoplasm & & \\
\hline $\begin{array}{l}\text { Hyperphosphorylated } \\
\text { TDP-43 }\end{array}$ & $\begin{array}{l}\text { ALS } \\
\text { frontotemporal lobar degeneration } \\
\text { AD }\end{array}$ & $\begin{array}{l}\text { neuron, nucleus, } \\
\text { cytoplasm }\end{array}$ & & \\
\hline
\end{tabular}

SOD1 = Superoxide dismutase I; FTDP-17 = frontotemporal dementia and parkinsonism linked to chromosome 17.

es of autosomal dominant genetic transmission have an early onset and a fast progression, whereas sporadic cases have a late onset and a slow progression linked, at least in part, to the cellular senescence of the central nervous system (CNS). They correspond to a progressive neuronal degeneration that is long and silent, and that always begins in a specific and localized functional-anatomical structure.

In all neurodegenerative diseases, autopsies reveal the presence of endogenous pathogenic proteins called amyloid proteins (AP), which are proteins that misfold out of their physiological conformation to form $\beta$-sheet strands. These AP might be specific to one disease, like huntingtin or amyloid $\beta(A \beta)$, or found in various neurodegenerative conditions, like $\alpha$-synuclein or the phosphorylated TAR DNA-binding protein 43 (TDP-43) (table 1). These AP are water-insoluble and precipitate by generally forming large deposits that are detected due to specific and localized stains within or outside brain cells. The knowledge of their mechanisms of manifestation has developed through progress in molecular genetics. These advances have allowed researchers to identify genetic mutations that underlie familial forms and to describe the associated metabolic alterations, leading to the char- acterization of the origin of these kinds of neurodegeneration. Noteworthy, these same mutations have been proven to have the same effects in patients without a known family history. This made it possible to compare the two kinds of disease and use the same models to observe their effects. However, as the metabolic pathway altered by the mutation is downstream in the overall pathological event, an animal model carrying a mutation corresponding to the familial form of a disease might not reflect its sporadic form. In that case, the etiology of the disease might be an upstream event. A typical illustration of this situation is given by the transgenic animal models of $\mathrm{AD}$.

Isolating pathogenic genes, transferring them to healthy cells, creating animals where human pathogenic genes are expressed, and producing mice that lack the corresponding healthy gene or that are carriers of the defective mutant gene are the primary experimental models. These models are complemented by the experimental study of the toxic effects of isolated AP. The simplest models involve applying AP to cell organelles such as the nucleus or DNA, the mitochondria, endoplasmic reticulum or synaptic cleft; this allows their direct subcellular toxicity to be observed $[2,3]$. Exposing cultured brain 


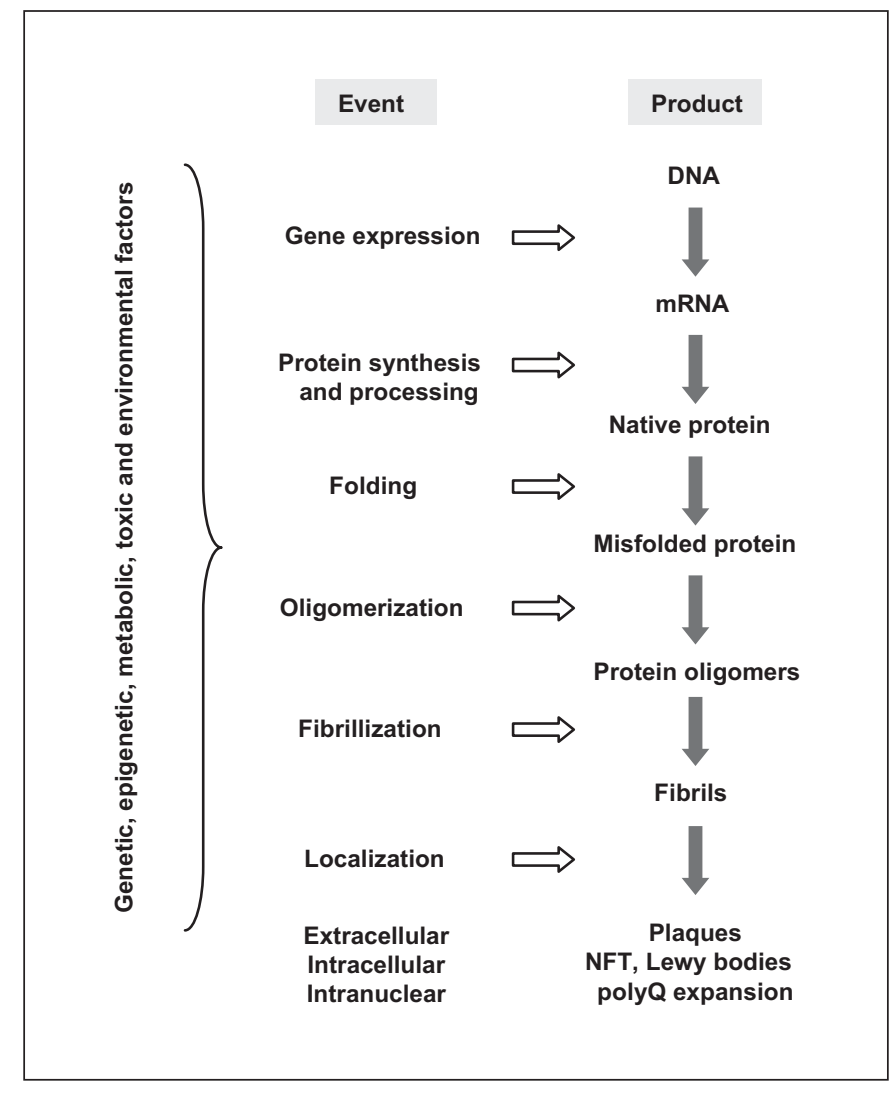

Fig. 1. Sequence of events and products formed leading to the histopathological phenotype of neurodegeneration. The native protein is misfolded, then it forms oligomers and fibrils which precipitate into cells either in nuclei (polyQ), in cytoplasm (neurofibrillary tangles, NFT, and Lewy bodies) or outside cells (senile plaques). Modified from Forman et al. [6].

cells (such as neurons, astrocytes and oligodendrocytes) to AP makes it possible to measure the particular sensitivity of certain functional structures (such as cholinergic, dopaminergic and GABAergic fibers) as well as the chronology of lesions and their cellular and intercellular consequences.

The direct administration of AP to animals reveals the pathological process in its entirety, from its repercussions on different brain structures and functions to its progression. These models involve a more complex process as it is still not possible to reproduce the disease by simply injecting AP. Other adjuvants are thus necessary as prooxidants or oxidation catalysts [4]. The intracerebral administration of AP can also provide useful information.

A major discovery in this field was the detection of prions, which are infectious proteins capable of causing human-transmissible neurodegeneration (CreutzfeldtJakob disease) [5]. Many observations suggest that these $\mathrm{AP}$ are generated by the same pathological mechanism although their final compositions are different [6].

New pharmacological treatments that may be common to all neurodegenerative diseases, or at least to some of them, would indicate the presence of a common pathological mechanism [7].

\section{Structural Abnormality Common to AP}

The analogy between different AP can be first explained by similar abnormalities in their formation and maturation (misfolding) of one or many proteins becoming 'amyloidogenic', in that they have an abnormal structural conformation that can polymerize and can form oligomers that aggregate into protofibrils and then into stable fibrils. Since such alteration renders them insoluble, these proteinaceous structures result in amyloid deposits (fig. 1). These protofibrils are, among other things, catalysts of fibril formation. Although the primary structure of each AP is normal and physiological, the polypeptide structure may adopt various 3-D conformational structures. The final conformation is not obtained via the formation of requisite intermediate structures; instead, it occurs stochastically, with the selection of the final shape of the physiological proteins being determined by chaperones. Chaperones seem to play three main roles: they direct protein synthesis into physiological conformations, they prevent protein aggregation, and they eliminate aberrant proteins. The formation of amyloidogenic proteins results from the alteration of one or many of these protein-manufacturing assistants [8]. This alteration has several known and likely to be interrelated causes that are genetic, metabolic, toxic and environmental in nature. Cellular aging is also a contributing factor as it limits the potential for protein synthesis and clearance. Cellular stress is another known cause and is accompanied by an increased formation of chaperones (heat shock proteins) that, nonetheless, are probably insufficient to hinder the increase in protein synthesis $[9,10]$.

Each neurodegenerative disease is characterized by the in situ presence of one or more AP generated in a specific functional-anatomical structure as illustrated in table 1 . These proteins have very different compositions, but they all share the same abnormal conformation that fosters their oligomerization and their resistance to cell clearance mechanisms. This structural abnormality appears to be independent of the proteins' respective amino 
acid sequences [11]. The hypothesis of a common abnormal structural conformation remains to be demonstrated, but it is nevertheless substantiated by the fact that an amyloidogenic substance can cause the formation of fibrils in the presence of other amyloidogenic substances $[12,13]$.

At the same time, hippocampal neuronal cultures from tau protein knockout mice do not degenerate from the administration of $A \beta$ alone, but rather when it is associated with the tau protein, which shows that both AP are required in order to induce neurodegeneration in this model [14]. In vivo experiments show that amyloidosis can be caused by one type of protein, but it is most often caused by two or three types. In most cases of AD, the amyloidosis is caused by two types of associated proteins (A $\beta$ and tau), while tau is associated with $S \alpha$ in some cases of PD. In other forms such as Down syndrome and Guam Parkinson's dementia, three AP are associated: $A \beta$, tau and $S \alpha$. Lewy bodies contain several and sometimes many proteins, with a recent study identifying up to 296 of them [15], which indicates that other proteins have yet to be identified. Coprecipitation phenomena also play a role, which could explain why protein binds to other substances (cholesterol) in the deposits. No matter what their assemblies are, these proteins precipitate within or outside brain cells and, depending on the case, form plaques, filaments, aggregates or bundles of fibrils collectively referred to as neuritic plaques. Their formation poses multiple problems. Although it is not yet clear whether plaque formation is caused by excessive AP formation, a diminished AP clearance or both, together they clearly suggest the potential effectiveness of multiple types of treatment that involve suppressing the formation of amyloidogenic substances, increasing their rate of elimination or employing a combination of the two.

Interestingly, AP deposits are only found in the encephalon, whereas the mutation affects the entire body. This has been demonstrated by the presence of high concentrations of amyloidogenic substances in plasma and cerebrospinal fluid (CSF) without peripheral deposits. This is probably the sign of a vulnerability that is specific to the CNS as peripheral organs seem to resist the aggregation of amyloidogenic substances. Moreover, particular lesions target neurons in the CNS, for example dopaminergic fibers in the corpus striatum (PD) or cholinergic fibers in the hippocampus and the neocortex (AD), depending on the nature of the disease in question. Restriction to the CNS, and the selectivity of the initial localized target are phenomena for which there is currently no explanation. However, a deregulation of cere- bral cholesterol metabolism, which for the most part is independent from the cholesterol metabolism of peripheral organs, can explain the central neurological impact. In particular, a high cholesterol diet has recently been shown to reduce the expression of the endoplasmic reticulum chaperones calreticulin and the glucose-regulated proteins 78 and 94 in the cortical areas displaying amyloid deposits [16]. By the same token, a local deficiency in growth factor might determine the selectivity of the initial target.

Overall, neurodegeneration seems to be attributable to multiple causes rather than a single cause. Genetic mutations are certainly one factor, but they do not satisfactorily explain sporadic cases, for which pathogenic factors of a toxic, metabolic, infectious or environmental nature come into play [17]. Cellular aging and, in particular, the progressive decrease in mitochondrial functions are aggravating factors that can be explained in part by mutations in mitochondrial genes and nuclear genes that code for mitochondrial proteins [18].

\section{AP Characteristics}

$\mathrm{AD}$ is histologically characterized by the formation of senile plaques and neurofibrillary tangles. Three mutated genes are involved in the familial form of the disease: $A \beta$ precursor protein (APP), presenilin 1 (PS1) and presenilin 2 (PS2). These amyloid deposits, which could be intravascular, intraneuronal or extracellular, contain $A \beta_{1-40}$ and $A \beta_{1-42}$, two products of the amyloidogenic cleavage pathway of APP. APP is a long-chain transmembrane protein, whose precise physiological function is not yet fully understood. Recent data strongly support a role for APP in embryonic neural organogenesis [19], neurite outgrowth [20] and synaptogenesis [21]. Moreover, using proteomic and bioinformatic tools revealed that APP might interact with more than 30 proteins, suggesting that many physiological processes might be affected [22]. Other authors reported that cholesterol regulates the metabolism of APP $[23,24]$, and that APP may regulate the cerebral cholesterol metabolism [25]. In any case, APP is cleaved by three types of proteases: $\alpha$-, $\beta$ - and $\gamma$-secretases. The APP proteolysis by $\beta$ - and $\gamma$-secretase results in the production of $A \beta_{1-40}$ and $A \beta_{1-42}$ and defines the amyloidogenic pathway, as opposed to the proteolytic cleavage of APP by $\alpha$-and $\gamma$-secretase, which produces noncytotoxic soluble fragments. $\beta$-Secretase, or BACE1, is an aspartyl protease that cleaves APP on the luminal side of a cell, and its activity is the rate-limiting step for $A \beta$ production. APP 
cleavage releases the fragment C99, which undergoes further processing by $\gamma$-secretase. BACE1 expression and enzymatic activity were found to be increased in sporadic $A D$ [26] and to be tightly correlated with $A \beta_{1-x x}$ production [27]. $\gamma$-Secretase is the second protease that participates in APP proteolysis and $A \beta_{1-42}$ production in the amyloidogenic pathway. $\gamma$-Secretase is an aspartyl protease that belongs to the intramembrane-cleaving protease family that cleaves the APP C-terminal fragment C99 to produce the amyloid species $A \beta_{1-42}$ and $A \beta_{1-40}$. $\gamma$-Secretase is a complex that includes four proteins: presenilin (PS1 or PS2), nicastrin, anterior pharynx defective 1 and presenilin enhancer 2, which are required for its protease activity [28]. Presenilins are represented by two members, PS1 encoded by chromosome 14 and PS2 encoded by chromosome 1 . PS1 supports the catalytic activity of the enzymatic complex, and its exact structure and catalytic site have only recently been identified $[29,30]$. Autosomal dominant mutations of APP, PS1 or PS2 genes describe the familial early-onset $\mathrm{AD}$ and account for 3 $5 \%$ of the total AD cases. These mutations result in an increase in amyloid peptide production and plaque formation.

Nonsteroidal anti-inflammatory drugs (NSAID) decrease the prevalence of $\mathrm{AD}$ and reduce the in vitro production of $A \beta_{1-40}$ and $A \beta_{1-42}$. Statins have the same clinical effect, perhaps through their cholesterol-lowering action.

All of these observations suggest the usefulness of other pharmacological treatments that aim either to suppress the formation of $A \beta_{1-40}$ and $A \beta_{1-42}$ or to further their elimination. The first goal involves either activating $\alpha$-secretase or inhibiting either $\beta$ - or $\gamma$-secretase. Neprilysin experimentally increases the elimination of $A \beta$, while metal chelators inhibit its aggregation. Another elegant method consists in immunizing patients with a vaccine containing $A \beta_{1-40}$ and $A \beta_{1-42}$. Unfortunately, a phase II trial revealed that the preparation used induced severe neurological toxicity (meningoencephalitis). However, other preparations could be available in the future. In addition, therapeutic strategies based on the administration of specific immunoglobulins, so-called passive immunization, are currently being developed.

Hyperphosphorylated tau protein deposits are also seen in $\mathrm{AD}$ neuropathology and are intracellular. This physiological protein attaches itself to microtubules and stabilizes them, thereby presenting a certain degree of increased phosphorylation in tau pathologies. In these cases, the protein is hyperphosphorylated and loses its microtubule-stabilizing function, bringing about impair- ment in neuronal transport [31]. The polyphosphorylated tau protein aggregates then form filaments that make up neurofibrillary tangles [32]. Polyphosphorylated tau protein deposits can be seen not only in neurons, but also in glial cells.

$\mathrm{AD}$ is characterized by the presence of Lewy bodies in the cytoplasm of dopaminergic fibers. They contain $S \alpha$, a small presynaptic protein whose gene has been mutated (MAPT). The functions of this protein are currently unknown. Its structural conformation is modified by excess $\beta$-pleated sheets, which facilitate its polymerization and the formation of amyloid fibrils. The presence of Lewy bodies is associated with different forms of dementia such as AD and ALS. It is interesting to note that rotenone, a mitochondrial complex I inhibitor, also causes the formation of fibrils in rats, which shows that this form of neurodegeneration may have an environmental cause. This toxicity is increased by oxidative stress. The accumulation of $S \alpha$ may be due to its excess formation, but also to its deficient elimination. Mutations in genes that code for two enzymes that break down $\mathrm{S} \alpha$, parkin (E3 ligase) and ubiquitin carboxy-terminal hydrolase L1, have been observed in $\mathrm{AD}$; their inactivation may be one of the causes of the disease. The therapeutic objective is thus to activate them. The expansion of polyglutamine repeat forms the tract of huntingtin, the AP associated with HD, spinobulbar muscular atrophy (Kennedy's disease) and different forms of spinocerebellar ataxia. Contrary to the mutated genes of the diseases mentioned above, the genes involved here have an increased, and therefore pathological, activity. The normal polyglutamine tract is composed of about 30 glutamine residues. The mutation causes an extension of the chain that expands the glutamine repeat, thereby producing longer unstable chains. In vitro, the mutated chains form aggregates or fibrils characterized by a predominance of $\beta$ pleated sheets as in other amyloidoses. These fibrils are neurotoxic; they are localized in neuronal nuclei and contain ubiquitin, which has led to the hypothesis of a decreased proteasome activity.

ALS is characterized by motor neuron loss, gliosis and inclusions containing ubiquitin both found in intact and impaired motor neurons. The protein composition of these inclusions is unknown. Many mutations have been observed, and the one most studied codes for $\mathrm{Cu} / \mathrm{Zn}$-dependent superoxide dismutase 1 (SOD1). Its activity relies on the coordination with $\mathrm{Zn}^{2+}$ and $\mathrm{Cu}^{2+}$. A recent study showed that the loss of such coordination with $\mathrm{Zn}^{2+}$ is a prerequisite for the SOD1 misfolding and aggregation [33]. However, mutations of the SOD1 gene account for 
only $20 \%$ of the familial form of ALS (fALS; $10 \%$ of ALS cases). The identification of the protein TDP-43 as a major component of ALS permitted researchers to fill this gap. TDP-43 is a 414 -aa protein that belongs to the heterogeneous nuclear ribonucleoprotein that contains two mRNA recognition motives [34]. This protein is normally present in the nucleus, but abnormal phosphorylation or mutation has been described to lead to its accumulation in the cytosol of neuronal or glial cells, where it aggregates and forms cytoplasmic inclusions. These inclusions were found in motor neurons and muscle cells of patients suffering from ALS. Twenty mutations of the TARDBP gene have been described to date, 12 exclusively seen in fALS and 8 in sporadic ALS. Interestingly, to date observations have seemed to indicate that fALS patients who carry a SOD1 gene mutation do not carry any of the TARDBP mutations nor do they display any TDP-43 hyperphosphorylation.

Physiological prions are small protein molecules linked to glycosylphosphatidylinositol and are mainly formed of $\alpha$-helices. Protease-resistant prions (PrP) are abnormal forms of physiological prions. Contrary to normal physiological prions, PrP often contain $\beta$-pleated sheets. These are amyloidogenic substances that form aggregates and develop amyloid-specific neuronal toxicity. However, the slowness of the pathological progression and the inability to reproduce the infection in animals seem to point to a more complex mechanism involving a second protein (protein X). The concept of direct PrP transmission without the involvement of a gene (i.e. a DNA-independent process) has not yet been validated in humans.

\section{Toxic Effects of AP}

These effects range from cellular lesions (damage to gene transcription machinery, degradation of mitochondrial function, oxidative stress, protein retention and apoptosis induction) to neuronal function problems (axonal transport and synaptic transmission inhibition, and excitotoxicity) $[6,35]$.

The common feature of all of these neurodegenerative diseases is the extreme functional-anatomical specificity of the initial targets, which involve dopaminergic neurons of the substantia nigra in $\mathrm{PD}$, cholinergic and monoaminergic neurons of the hippocampus and the cortex in $\mathrm{AD}$, cholinergic neurons of the corpus striatum in $\mathrm{HD}$, and spinal motor neurons and cholinergic cortical neurons in ALS. The highly targeted nature of these diseases can only be explained by a characteristic vulnerability of the structures involved. There is probably a genetic origin at play, but this seems to be only a partial answer; indeed, it has been observed in the case of HD that only the striatum is damaged, whereas the mutations affect all CNS cell types.

All AP develop direct neuronal toxicity, as evidenced experimentally on cultured neuronal cells and in mice that overexpress the genes responsible for these diseases in humans. However, the intensity of the clinical signs and the size/number of the AP deposits are not always correlated. Clinical signs may occur without deposits, while relatively large deposits can develop without clinical manifestation. For example, many more and larger amyloid plaques may be found in the brain tissue of healthy subjects than in $\mathrm{AD}$ patients, and in the same manner, it is not unusual that postmortem histological studies reveal less amyloid deposits in $\mathrm{AD}$ brains than in the average normal population.

Neurodegeneration seems to result from the juxtaposition of at least two toxic effects (double hit), mitochondrial functional impairment and oxidative stress, the latter generating or aggravating the former [36]. The main mitochondrial functions - oxidative phosphorylation, the limitation of the production of reactive oxygen species (ROS) and calcium homeostasis - are altered and then impaired. This results in the halting of ATP synthesis, the development of oxidative stress and the accumulation of $\mathrm{Ca}^{2+}$ ions (fig. 2). The reality of oxidative stress has clearly been demonstrated both experimentally and post mortem in patients with $\mathrm{AD}$ by evidence of its biological markers in the CNS, which include lipid peroxidation, protein nitration and glycation, and glycoxidation reactions. The accumulation of $\mathrm{Ca}^{2+}$ is particularly harmful to the CNS as it causes excitotoxicity. Mitochondrial impairment is followed by a decrease in basal cellular respiration due to the inhibition of cytochrome c oxidase. This impairment of the mitochondrial respiration chain is observed in all neurodegenerative diseases. The fact that it occurs only in the CNS is consistent with its close dependence on the supply of oxygen. Indeed, in addition to its great need for oxygen and its large capacity to use it, the brain has easily oxidizable substrates - polyunsaturated fatty acids, catecholamines and cholesterol - as well as specific ROS production systems and significant amounts of iron. However, its capacity to destroy ROS is quantitatively limited. In excess, ROS can trigger apoptosis through different mechanisms: the release of cytochrome $\mathrm{c}$ in the cytoplasm, the collapse of the membrane potential, the release of apoptosis-inducing factor, the ac- 
Fig. 2. The generation of oxidative stress and its consequences. MPT = Mitochondrial permeability transition.

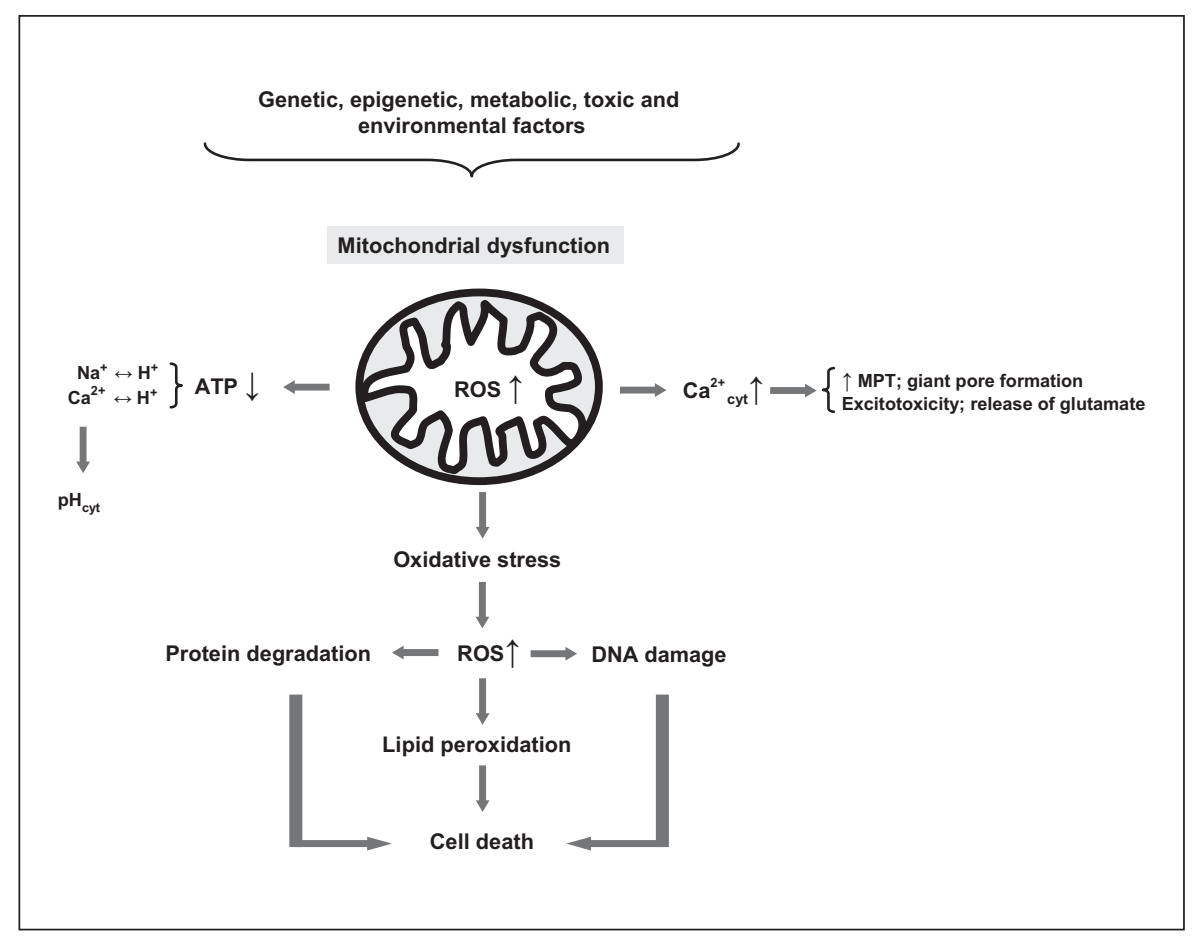

tivation of the caspase cascade (by second mitochondriaderived activator of caspases) and the opening of the giant pore. All of these apoptotic mechanisms are mitochondrial in origin, which underscores the major role of this organelle in neuronal degeneration.

The signs of excitotoxicity [37] observed in most neurodegenerative diseases are generated by a massive release and excess of excitatory amino acids, particularly glutamate. This stimulates two types of receptors: ionotropic and metabotropic. N-methyl-D-aspartate (NMDA) receptors are ionotropic; when depolarized, they allow the $\mathrm{Na}^{2+}$ and $\mathrm{Ca}^{2+}$ inward current into postsynaptic neurons, which increases and surpasses their energy capacity (depletion of ATP stores) and subjects them to oxidative stress. NMDA receptors and $\mathrm{Ca}^{2+}$ channels are concentrated in the synaptic cleft, which is thus subjected to an intense energy demand that is greater than the demand on other neuronal compartments. The synaptic cleft is therefore a very specific area of vulnerability, and it is where the first neuronal lesions of $\mathrm{AD}$ are observed in conjunction with the first signs of cognitive impairment [38]. The causal role of the overactivation of NMDA receptors in the development of cognitive impairment is validated by the inhibiting effect of memantine, which reduces both the stimulation of the receptors and cognitive impairment [39]. However, its efficacy remains lim- ited, probably because excitotoxicity is only one of the consequences of neurodegeneration.

Mitochondrial DNA (mtDNA) is particularly susceptible to free radical attack because, unlike nuclear DNA, it is not protected by histones, and because of its limited repair capacity and frequent mutations (heteroplasmy). Each cell contains numerous mtDNA copies, either mutated or nonmutated, on which a free radical attack can have different effects depending on the cell type and previous mutations. The coexistence of mutated or nonmutated mtDNA explains how the consequences of the disease can vary in intensity from absent to major. It has been observed that, in addition to an apparently specific mutation of the patient's mtDNA, an accumulation of other mutations in nuclear genes that encode mitochondrial translation may also occur [40]. The effects of mitochondrial mutations are cumulative, begin at a very young age and continue throughout life. Despite their relative quiescence, stem cells are a major source of the clonal expansion of mtDNA mutations and, therefore, of respiratory chain dysfunction. The observation of a high error frequency in the expression of mtDNA polymerase is in line with this hypothesis [41].

Most of the mitochondrial proteins are formed from nuclear genes and then translocated into the organelle. The result is that nuclear mutations underlie functional 
alterations of mitochondria, particularly oxidative phosphorylation. In fact, more than 70 nuclear genes code for the protein subunits of the respiratory chain (the OXPHOS complex), and hundreds of genes control their expression, assembly, function and renewal [42].

The observation that nuclear and mtDNA mutations result in impaired mitochondrial function demonstrates their significance in the development of neurodegeneration. This can only be aggravated by oxidative stress (fig. 2): the fact that the supply of oxygen to the cell, and thus to the mitochondria, is the same regardless of age (as it is a function of $\mathrm{PO}_{2}$ and, therefore, of atmospheric pressure) implies that any decrease in the capacity to utilize this oxygen supply corresponds to a relative oversupply of $\mathrm{O}_{2}$, which, when only partially reduced, results in ROS formation. This is probably how cellular aging plays a role in the progression of degenerative phenomena.

\section{Current Treatments for Neurodegenerative Diseases}

Current treatments are mainly symptomatic [43], but new disease-modifying drugs meant to slow down or stop the progression of the disease are now emerging.

\section{$A D$ and Treatments for Dementia}

\section{Palliative Treatments}

The goal of palliative treatments in this case is to compensate for the decreased activity of cholinergic neurons. In the following, these treatments are listed in order of increasing interest.

Some substances are meant to increase the synthesis and release of acetylcholine: lecithins and, more broadly, choline donors. These have not demonstrated any real activity. 4-Aminopyridine is, in theory, more useful: it blocks axon terminal $\mathrm{K}^{+}$channels, increases their action potential and stimulates the cellular uptake of $\mathrm{Ca}^{2+}$ and its effect on the release of acetylcholine. Clinical studies have yet to provide conclusive results.

Cholinergic agonists are of interest as they act directly on receptors. Receptors are preserved and remain functional in the case that neuronal functioning stops. Various compound agonists of the M1 subclass of postsynaptic muscarinic receptors and agonists of the $\alpha_{7}$ or $\alpha_{4} \beta_{2}$ subclass of nicotinic receptors are currently in development, either at a discovery stage or in phase I/phase II clinical trial [44]. Nicotine remains an excellent cholinergic agonist because it increases the release of acetylcholine through presynaptic nicotine receptors. It is also a stimulant of phosphorylative oxidation, while, clinically, it increases cognitive abilities. Epibatidine is a synthetic derivative of nicotine that displays the same properties. Other nicotine analogs deriving from epibatidine are currently being developed as a treatment for AD [45].

The medications most often used are inhibitors of acetylcholinesterase (AChE), which by inhibiting acetylcholine degradation by AChE maintain physiologically active acetylcholine levels in the brain. These drugs potentiate the acetylcholine released during presynaptic stimulation by increasing its local concentration and duration of action. Their activity presumes the existence of fibers that have remained functional and that are capable of releasing acetylcholine. These drugs also have few side effects at suitable dosages. At high dosages, they display muscular and peripheral muscarinic (parasympathomimetic) effects. The first inhibitor, tacrine, was released on the market in the early 1990s, but its use was hampered by high liver toxicity. Three AChE inhibitors are currently in use, i.e. donezepil (Aricept ${ }^{\circledR}$, Pfizer), rivastigmine (Exelon ${ }^{\circledR}$, Novartis) and galantamine (Reminyl ${ }^{\circledR}$, Janssen Pharmaceutica), which are devoid of liver toxicity. The true benefits of these AChE inhibitors for mild, moderate and severe $\mathrm{AD}$ cases as well as mild cognitive impairment are a matter of extensive studies and, consequently, of much discussion. New generations of AChE inhibitors with a multitarget design are currently at various stages of development $[46,44]$.

\section{Medications Targeting Underlying Causes:}

Disease-Modifying Drugs

The goal of these medications is to decrease the cellular concentration of $A \beta$. To do this, one could theoretically increase the activity of $\alpha$-secretases or decrease the activity of $\beta$ - and $\gamma$-secretases. The inhibition of $\beta$ secretases appears to be the most promising pathway as this enzyme belongs to the class of aspartic proteases. Other inhibitors of these proteases are already known, marketed and well-tolerated. The inhibition of $\gamma$-secretases is also possible; however, currently known substances have proven to be toxic. If $A \beta_{1-40}$ and $A \beta_{1-42}$ generation cannot be decreased, it is theoretically possible to increase their clearance by either degradation or excretion. Another approach consists in 'neutralizing' the amyloid peptide. Many compounds of various chemical structures are now being developed to bind to $A \beta_{1-42}$ and prevent its aggregation into neurotoxic amyloid oligomeric species. Such compounds are also thought to be able to prevent $A \beta_{1-42}$ from reaching its intracellular targets such as the mitochondria respiratory chain $[46,47]$. 
It is experimentally possible to inhibit the hyperphosphorylation of the tau protein. Many kinases are capable of phosphorylating this protein, but only three of them seem to be involved in the pathological hyperphosphorylation process: tau protein kinases I (or glycogen synthase kinase $3 \beta$ ) and II (or cell division protein kinase 5), and extracellular signal-regulated kinase 2. Various substances inhibit these kinases, and those that are the most selective and that can cross the blood-brain barrier (BBB) are chosen for therapy [32].

Medications with a More General Action

These substances are used for other purposes, but epidemiological studies have shown that they could limit the prevalence and severity of AD.

Inhibitors of Excitotoxicity. Here, two kinds of action have been proposed. The first consists in inhibiting the stimulation of NMDA receptors; memantine, riluzole, and D-cycloserine (a partial agonist) inhibit these receptors. However, the combination of memantine with donepezil may be avoided as the second potentiates the toxic effect of the first [48]. The second possibility consists in activating $\alpha$-amino-3-hydroxy-5-methyl-4-isoxazolepropionic acid receptors with ampakines or with nootropic drugs such as propiracetam, oxiracetam, or aniracetam. The results obtained so far are limited.

Antioxidants. Antioxidants are meant to limit the effects of ROS. In fact, many of them have not been proven to be effective, probably because their tissue diffusion is not sufficient to induce effective cellular and subcellular (mitochondrial) concentrations. This is the reason why combinations are suggested, such as vitamin $\mathrm{E}$ and selenium.

Several compounds of natural origin have demonstrated clinical efficacy in mild-to-moderate forms of AD. A naturally occurring polyphenol compound transresveratrol [49], is found in a variety of plants and, notably, in the skin of grapes. Regular and moderate consumption of red wine delays and limits the severity of senile dementias [50]. Its cytoprotective effects can be observed in multiple organs, particularly the brain: it has been shown to stabilize or restore the functions of mitochondria that are subjected to an experimental ischemiareperfusion sequence [51]. Currently, trans-resveratrol is used as a food supplement. The standardized Ginkgo biloba extract EGb761 also demonstrated the same clinical efficacy as donezepil although acting through a different mechanism of action [52]. The use of EGb761 as a preventive treatment against $\mathrm{AD}$ is currently being investigated in the GuidAge study, which is the most important clini- cal trial ever conducted in Europe on the prevention of $\mathrm{AD}$ and whose results should be published in 2010 [53].

Clioquinol is a potentially useful substance. Also a polyphenol, it delays the appearance of cognitive impairment and experimentally dissociates amyloid plaques in postmortem samples. It seems to act through the chelation of $\mathrm{Cu}^{2+}$ and $\mathrm{Zn}^{2+}$, which are coenzymes involved in oxidation reactions.

Other efforts in drug development for $\mathrm{AD}$ have recently been reviewed [46].

\section{Parkinson's Disease}

Current Palliative Treatments

The goal of these treatments is to compensate for the dopaminergic deficit by the administration of levodopa, a precursor of dopamine. Levodopa is associated with different substances that either prevent its peripheral conversion (carbidopa and benserazide) or inhibit the degradation of dopamine by catechol-O-methyl transferase (entacapone and tolcapone). It is also possible to use other dopaminergic receptor agonists $\left(D_{2}\right)$ such as ergot derivatives (bromocriptine, pergolide, cabergoline) or other substances such as pramipexole, ropinirole and rotigotine.

Another approach, which complements the one mentioned above, is to inhibit the cholinergic system, an antagonist of the dopaminergic system. The central muscarinic receptor antagonists used in this case are benztropine, trihexyphenidyl and diphenhydramine.

Amantadine acts in a complementary manner by blocking glutamate NMDA receptors, which then limits the development of excitotoxicity. Selegiline is also a substance of interest. Used as a monoamine oxidase B inhibitor, it does not act through enzymatic inhibition, but by protecting mitochondrial functions.

\section{Medications in Development}

These medications are also palliative, but their goal is to regulate neuronal functioning as a whole by activating the functional synergy of dopamine and by inhibiting its antagonists. The medications currently being studied have recently been reviewed [54]. These include $5-\mathrm{HT}_{1 \mathrm{~A}}$ receptor agonists, which inhibit dyskinesias caused by levodopa and GABAergics. Adenosine $\mathrm{A}_{2 \mathrm{~A}}$ receptor antagonists appear to have two advantages. These $\mathrm{A}_{2 \mathrm{~A}}$ receptors are coexpressed with $\mathrm{D}_{2}$ receptors in the striatum and physiologically inhibit the release of GABA. $\mathrm{A}_{2 \mathrm{~A}}$ antagonists thus have an indirect GABAergic action and seem to have an independent neuroprotective effect. 
Opioid inhibition is, at present, purely experimental. This inhibition is based on increasing preproenkephalin A activity in PD, which is responsive to and corrected by levodopa. Dyskinesias are decreased by $\mu$ - and $\delta$-opioid receptor antagonists, which have an independent neuroprotective effect.

\section{Huntington's Disease}

The treatment here is symptomatic and mirrors that of PD. It consists of dopaminergic receptor antagonists, i.e. the neuroleptics haloperidol and chlorpromazine. Theoretically, muscarinic and GABAergic agonists should be effective, but they are not used.

\section{Amyotrophic Lateral Sclerosis}

The treatment of this disease is symptomatic. It consists of (i) potentiating GABA using riluzole, which inhibits its reuptake, and (ii) decreasing the release of glutamate in the synaptic cleft using gabapentin. Recently, the use of lithium carbonate appears to be of interest [55], based on both clinical and experimental data. Lithium delays the progression and decreases the severity of the disease. In a genetic ALS animal model, it developed neuroprotection by increasing autophagy and the number of mitochondria of motoneurons, and by decreasing astrogliosis.

\section{Future Therapeutic Strategies}

Current research avenues include genetic stem cell grafting and the pharmacological stimulation of endogenous neurogenesis, the development of new small molecules that target iron-deleterious pathways, growth factors and collagen injections in mitochondria. These topics fall outside the scope of this study, and only some new pharmacological targets will be discussed here. The development of small molecules that bind amyloid entities to prevent their aggregation into more neurotoxic species has recently been presented $[44,32]$.

\section{Normalization of Cerebral Cholesterol Metabolism}

$\mathrm{AD}$ is always accompanied by a deregulation of the cerebral cholesterol metabolism. Although this metabolism does not have precisely the same mechanism as the systemic and peripheral cholesterol metabolisms, many arguments point to an association between atherosclerosis and $\mathrm{AD}$. The first arguments rely on clinical signs: atherosclerosis and $\mathrm{AD}$ are frequently associated as there is a convergence of genes implicated in both diseases [56] and, even more convincingly, as the statins lovastatin, simvastatin and pravastatin have both beneficial and cholesterol-lowering effects in AD [57-59]. However, it is also possible that the beneficial effect of statins in $\mathrm{AD}$ might be due only in part to their cholesterol-lowering properties.

The second arguments consider biological phenomena such as the levels of the translocator protein $18 \mathrm{kDa}$ (TSPO), previously known as the peripheral-type benzodiazepine receptor. TSPO is a high-affinity drug- and cholesterol-binding cholesterol transfer protein involved in the cholesterol transport into mitochondria, a limiting factor in steroid synthesis. TSPO levels are increased in all neurodegenerative diseases and, particularly, in $\mathrm{AD}$ [60]. This increase is mainly observed in glial cells and, to a lesser degree, in neurons that physiologically have a low concentration of TSPO. Interestingly, the same variations are observed in other neurodegenerative diseases such as PD, HD and multiple sclerosis, and in certain epilepsy models. The concentration of the endozepine diazepam-binding inhibitor, an acyl-CoA-binding protein, the endogenous ligand of TSPO and probably its physiological activator, is increased in parallel to that of TSPO in peripheral nerve lesions [61]. When these neurons are regenerated, TSPO and diazepam-binding inhibitor concentrations return to normal. This temporary increase in TSPO activity can be interpreted as an increased uptake of cholesterol that lasts as long as necessary to restore internal mitochondrial membranes [62] and protein uptake $[63,64]$, and that also stimulates the formation of glial cells and gliosis.

Although it is reasonable to believe that neurodegenerative diseases are associated with a deregulation of the cholesterol metabolism, and that they lead to a decrease in neurosteroid formation, the question remains as to why the phenomenon of degeneration attacks the CNS exclusively.

It must first be recognized that the roles and metabolism of cerebral cholesterol are very different from those of peripheral organs, particularly those of the liver. To a certain degree, the former is little dependent on the latter. The concentrations of cerebral cholesterol are approximately 8-10 times higher, and this kind of cholesterol mainly comes in a free nonesterified form that is concentrated in cell membranes, myelin sheaths, synaptic vesicles and pre- and postsynaptic terminals. Cerebral cholesterol is primarily transported by very-low-density lipoprotein (VLDL), low-density lipoprotein (LDL) and apolipoprotein E (ApoE). Cerebral cholesterol is, for the most part, synthesized locally and mainly at the beginning of CNS 
development and then stored in the brain. This initial stage of intense synthesis then decreases, with required cholesterol mostly coming from prenatal stores and via in situ synthesis by astrocytes. Postnatal accumulation lasts many years. In humans, the $t_{1 / 2}$ of cerebral cholesterol has been calculated at 5 years, and its renewal rate is $0.03 \%$ per day compared to $0.7 \%$ for the entire body [65].

Cerebral cholesterol is successively converted in the mitochondrial matrix of glial cells into $22 \mathrm{R}-\mathrm{OH}$-cholesterol, 20,22-OH-cholesterol and, then, pregnenolone. This last substance, which is secreted in the cytoplasm, acts as a substrate in the endogenous formation of neurosteroids such as 17-OH-pregnenolone and dehydroepiandrosterone, and their sulfates, as well as allopregnanolone [66]. The final phase of neurosteroid synthesis takes place in the endoplasmic reticulum. Many molecules are created that play specific local autocrine or paracrine roles in neuronal survival and function. They regulate different behavioral functions (anxiolytic, antiphobic, antidepressant and antipsychotic action) by modulating GABA, NMDA and $\sigma$-receptors. Common characteristics of these neurosteroids include their limited localized action, their very low (nanomolar) active concentrations, which differ from those of systemic corticosteroids, their high diffusion across the $\mathrm{BBB}$, and their rapid nongenomic action. Another cholesterol fraction is oxidized into 24S-OH-cholesterol by CYP46A1. This neuronal endoplasmic reticulum enzyme is localized solely in the CNS. This metabolite crosses the BBB and is eliminated in the plasma and CSF. Its plasma concentrations are a good reflection of cerebral cholesterol concentrations. 24S-OH-cholesterol is also a powerful 3-OH-3-methylglutaryl-CoA reductase inhibitor, which suggests that it limits cerebral cholesterol synthesis through negative feedback. At the same time, it activates liver $\mathrm{X}$ receptors that bind to it and esterifies plasma cholesterol. Other oxidized cholesterol metabolites that have been described are $25-\mathrm{OH}-, 7-\beta-\mathrm{OH}-$ and 7-ketocholesterol. Their formation depends on that of ROS. Then, they are esterified either directly or after conversion, and subsequently taken up by lipoproteins.

The endoplasmic reticulum ensures a continuous concentration of free cellular cholesterol. Any excess beyond these two metabolic pathways is secreted by brain cells and partially esterified. The increase in esterified cholesterol increases the formation of $A \beta$ [67]. At the same time, competing inhibitors of acyl-CoA:cholesterol acyltransferase (ACAT) reduce the formation of cholesterol esters and $A \beta$ in a dose-dependent manner, while increasing free cholesterol.

Neurodegenerative Disease Treatments
In $\mathrm{AD}$, an increase in free esterified and total plasma cholesterol is often observed. Associated with an increased neuronal transport by ApoE (VLDL), this increase may explain excessive stores of cholesterol in the CNS. It is therefore even more plausible that the activity of lecithin-cholesterol acyltransferase, which ensures the reverse transport, is reduced.

Cholesterol accumulates in amyloid plaques. High cholesterol concentrations stimulate the formation of $A \beta$, while lower concentrations inhibit its formation and stimulate the nonamyloidogenic cleavage of APP by $\alpha-$ secretases. $A \beta_{1-40}$ then forms and inhibits the binding of cholesterol to LDL. A $\beta_{1-42}$ also inhibits this binding as well as that of cholesterol to ApoE [25]. The plasma and CSF concentrations of $24 \mathrm{~S}-\mathrm{OH}$-cholesterol increase at the beginning of $\mathrm{AD}[68,69]$ and then subsequently decrease, suggesting a deficiency in the cerebral cholesterol metabolism.

As the deregulation of the cerebral cholesterol metabolism and the formation of amyloid deposits are closely associated, the questions are whether the two effects are linked (which is probable) and, if so, which causes the other? Does $A \beta$ induce the alteration of the cholesterol metabolism, or is the deregulation of the cerebral cholesterol metabolism one of the causes of amyloid deposits?

The first hypothesis is based on the observation that $A \beta_{1-40}$ is a pathological substance that increases concentrations of free extracellular cholesterol, which is toxic and is a component of amyloid plaques. $A \beta_{1-42}$ experimentally blocks the extracellular exchange of cholesterol by inhibiting the binding of cholesterol to its transporters LDL (cellular influx) and ApoE (efflux) [25]. The increase in glial cell TSPO concentrations in AD should correspond to an increase in the synthesis of pregnenolone. Although a discrete increase in its concentration is observed, it is not significant and is lower than expected, which suggests an altered functional state of TSPO. Another possible cause is thought to be TSPO polymerization induced by ROS [70]; another would be a relative deficiency in endozepine, its endogenous ligand [60]. At the same time, the concentration of 22R-OH-cholesterol, an intermediary metabolite of pregnenolone synthesis, is significantly lowered. This metabolite develops stereospecific neuroprotective effects [71]. A resulting conclusion could be that even an additional supply of cholesterol to depleted brain cells is insufficient [60]. This is obviously a very promising pharmacological target: natural derivatives of spirostenols seem to be able to reproduce the effects of $22 \mathrm{R}-\mathrm{OH}$-cholesterol and are currently in development $[72,73]$.

Pharmacology 2010;85:1-17 
The second hypothesis assumes a direct cholesterol involvement in the formation of $A \beta$. Its first argument is epidemiological: cholesterol-lowering drugs limit and reduce the formation of amyloid plaques. In pretreatment $\mathrm{AD}$ patients, we see an increase in total plasma cholesterol, essentially from LDL, the form in which cholesterol enters neurons. On the other hand, high-density lipoprotein (HDL), the form that picks up extracellular cholesterol, is decreased. Normalizing both HDL and LDL reduces the severity of $\mathrm{AD}$.

ApoE, particularly ApoE4, mediates the uptake of lipoproteins (VLDL and LDL) into neurons whether or not they are associated with the $A \beta$ monomer. Cholesterol is then released. A fraction of ApoE is broken down in the lysosomes, and the rest remains associated with $A \beta$, thereby causing the formation of fibrils, which are then secreted in the extracellular space where they form amyloid plaques, particularly when cholesterol is associated with the ApoE allele $\varepsilon 4$ isoform. Various formation models have been proposed [74]. One can therefore observe that the most cholesterol-rich lipoproteins (VLDL and LDL) associated with ApoE4 directly generate $A \beta$ from APP. The conversion mechanism of soluble $A \beta$ into amyloid fibrils is unknown. This conversion probably occurs in microdomains containing cholesterol, sphingomyelin and galactosphingolipids, and depends on the cellular ACAT activity. As an endoplasmic reticulum enzyme, ACAT esterifies excess cholesterol by incorporating it into long-chain fatty acids. The increase in this form of esterified cholesterol in turn causes the increase in the synthesis of $A \beta$ in a dose-dependent manner [67]. The authors therefore conclude that inhibitors of this enzyme are useful in the treatment of AD.

It is currently not possible to favor either one of these two hypotheses, but they have led to two different therapeutic options. The first option attempts to normalize the cerebral cholesterol metabolism and employs statin-type compounds presenting greater cerebral bioavailability, 24S-OH-cholesterol analogs or inhibitors of its degradation and, more generally, combined cholesterol-lowering treatments. Added to this are neuroprotective substances acting in place of $22 \mathrm{R}-\mathrm{OH}$-cholesterol. The second hypothesis has already been discussed (see above). It involves trying to halt the production of amyloid plaques by inhibiting their formation or by causing their elimination. ACAT inhibitors are currently also studied.

Niemann-Pick disease is a genetic form of neurodegeneration in which there is an accumulation of free cholesterol and other lipids in the thalamus, cerebellum (Purkinje cells) and peripheral organs (liver and spleen).
An accumulation of cholesterol precedes the onset of neurodegeneration signs, suggesting that the alteration in the cholesterol metabolism causes or worsens this disease.

In $\mathrm{HD}$, the cerebral cholesterol metabolism is also profoundly altered, but in a different way than in $\mathrm{AD}$. In this case, the toxic mutant huntingtin protein reduces the transcription of most genes regulating the metabolism of CNS cholesterol, particularly 3-OH-3-methylglutarylCoA reductase. The result is a decrease in local cholesterol synthesis. This occurs early and appears before clinical signs. Overall, the total and esterified cholesterols are lowered.

Many observations confirm this phenomenon as cultured striatal neurons that express mutated huntingtin rapidly die. They survive with the administration of cholesterol or with the addition of brain-derived neurotrophic factor $[75,76]$. Here, the metabolic impairment affects all organs. The decreased ability to form cholesterol is observed in the fibroblastomas of subjects with HD.

The decrease in cholesterol synthesis is accompanied by that in ubiquinone. Its exogenous supply reduces motor dysfunction in mice that overexpress the pathological mutation. Various fatty acids and ethyl-eicosapentaenoic acid also improve these dysfunctions by increasing membrane fluidity [77].

A decrease in cholesterol synthesis can also be observed in another neurodegenerative disease called Smith-Lemli-Opitz syndrome. The genetic error in this case translates into a deficiency in 7-dehydrocholesterol reductase, the final step in cholesterol synthesis.

In $\mathrm{PD}$, the alteration in the cerebral cholesterol metabolism is not completely understood. A study of Lewy bodies shows high concentrations of oxidized cholesterol derivatives. These are formed by the action of excess ROS during dopaminergic fiber degeneration, with dopamine oxidation itself acting as a producer of erythropoietin. Oxidized cholesterol derivatives, which are essentially aldehydes, are toxic substances that speed up the aggregation of $S \alpha$ and perpetuate the cycle of degeneration [78]. Moreover, a recent study reported that 27-OH-cholesterol reduces tyrosine hydroxylase and increases $\alpha$-synuclein expression in neuronal cell cultures [79]. Statins were shown to reduce $\alpha$-synuclein aggregation in an in vitro model of PD [80]. In a recent clinical study, lower serum LDL cholesterol was reported to be responsible for a higher occurrence of PD, and statins were shown to reduce PD occurrence [81]. These particular data raise the possibility that, although the well-established control of cholesterol synthesis may be the underlying mechanism of ac- 
tion of statins in neuroprotection, other pharmacological effects of these compounds, independent of their cholesterol-lowering properties, might account for their beneficial effect in neurodegenerative diseases $[82,83]$.

Overall, it is clear that an alteration in the cholesterol metabolism is the source of, or an aggravating factor in, each kind of neurodegeneration described here. The attempt to regulate this metabolism is currently a highly developed axis of research.

\section{Neuroprotection by Preservation of Mitochondrial Functions}

The impairment of mitochondrial functions is not the cause of the diseases, but a major step in the degenerative processes of cellular death. Indeed, the decrease in ATP synthesis leads to an excessive ROS generation, while the increase in matricial $\mathrm{Ca}^{2+}$ fragilizes neurons due to the toxic effects of glutamate. Mitochondrial dysfunctions have been described in almost all degenerative diseases, especially in $\mathrm{AD}$ and $\mathrm{PD}[84,85]$. The mitochondrial respiratory chain is blocked at its electron transfer enzymes, at cytochrome c oxidase (complex IV) and NADH ubiquinone oxidoreductase (complex I) in $\mathrm{AD}$ and $\mathrm{PD}$, respectively. Whatever the initial target, this results in a decrease in ATP synthesis, thus in a loss of available energy and an accumulation of $\mathrm{Ca}^{2+}$ inside the matrix. The relative excess of oxygen supply is used for ROS generation.

The mitochondrial defects in PD have been extensively studied [86]. They may be experimentally reproduced either with MPDP or with rotenone, both poisons of complex I. These deleterious effects are prevented by mitochondrial protectors as selegiline and nicotine [87]. These observations suggest that drugs which protect mitochondrial functions from various damages may be of value for preventing or delaying neurodegenerative diseases. Drugs used in anoxia may fulfill this goal, providing they are easily transferred through the BBB [88]. Interestingly, as mitochondrial functions may be regulated by a cholesterol signal [89], it is possible that normalizing the cholesterol metabolism may also improve mitochondrial functions.

\section{Neuroprotection by Reducing Neuroinflammation}

Neuroinflammation, with its activation of microglia and astrocytes, is a deleterious event shared by many, if not all, of the neurodegenerative diseases, contributing to the severity of the disease. Therefore, various therapeutic strategies emerged that aimed at reducing neuroinflammation. For example, in AD, NSAID have been used in experimental animal models and clinical trials as a potential treatment with various degrees of success. NSAID that showed efficacy were also agonists for the peroxisome proliferator-activated receptor- $\gamma$ (PPAR- $\gamma$ ), a nuclear hormone receptor broadly expressed in the CNS, which regulates the expression of various genes encoding proinflammatory proteins. It was further established that the inhibition of cyclooxygenase- 1 and cyclooxygenase- 2 had nothing to do with the beneficial effect displayed by the NSAID, and that the sole activation of PPAR- $\gamma$ was responsible for the reduction in the observed neuroinflammation. This led to the investigation of the effect of rosiglitazone and pioglitazone, two PPAR- $\gamma$ agonists currently on the market to treat type 2 diabetes, on various animal and cellular models of $\mathrm{AD}, \mathrm{PD}$, multiple sclerosis and ALS, where they inhibited the expression of proinflammatory cytokines, partially blocked the microglia and astroglia activation and reduced neurodegeneration [90]. In addition, the activation of PPAR- $\gamma$ by pioglitazone was shown to inhibit the expression of $\beta$-secretase and to reduce the amyloid burden in an animal model of AD [91]. Furthermore, two clinical trials reported the beneficial effect of rosiglitazone on the cognitive performance of AD subjects $[92,93]$. Taken together, these results indicate that PPAR- $\gamma$ is a promising therapeutic target in neurodegenerative disease therapy.

\section{Conclusion}

Medications that currently treat neurodegeneration are mainly symptomatic and/or palliative. The most recent research reported here opens up horizons for new etiological treatments and new drugs [44].

These diseases all have a common feature, neuronal degeneration, and are characterized by amyloidosis, the formation of abnormal proteins that are generated throughout almost the entire body, but that develop exclusively into a central neurological pathology. The proteins formed differ depending on the disease, but in all cases they result from an alteration in the formation of a particular protein based on a sequence of normal and physiological amino acids. The abnormality of the structural conformation can be seen in tertiary and quaternary protein structures: the proteins formed are amyloidogenic, resistant to physiological destruction mechanisms and capable of polymerizing.

These proteins are also water-insoluble and therefore precipitate in localized intra- or extracellular areas. No matter what the experimental model is, they always be- 
come toxic and are at least partially responsible for the disease in humans. A feasible pharmacological objective would be to inhibit this aberrant protein synthesis that is common to almost all neurodegenerative diseases, but that specifically affects the formation of a protein in a particular functional-anatomical structure depending on the disease in question. Two treatment options are indicated: the first involves the inhibition of this abnormal protein synthesis, while the second targets the elimination of the AP.

The treatment complexity of these diseases results from their underlying conditions. With the exception of genetic forms transmitted via dominant autosomal mode, these diseases develop slowly and remain clinically silent for a long time. The onset of symptoms is therefore the sign that the disease is established and, in theory, irreversible. The disease usually presents multiple deposit components, meaning that the pathology consists not of a single type of cerebral amyloidosis, but rather of many associated types that act together in toxic synergy.

There are two types of possible treatment to fight these diseases: preventive and curative. In the first case, it is clear that a neurodegenerative disease can have different causes that are genetic, toxic, environmental, metabolic and infectious in origin. These causes are often independent but cumulative, and each requires a targeted treatment. Research therefore centers on obtaining the earliest possible diagnostic, eliminating exogenous causes, and applying specific treatments. Different treatment options must then be adapted to the recognized causes. In some cases, the correction of abnormalities in the cerebral cholesterol metabolism appears to be at least partly effective.

All of these strategies are obviously still useful even when the disease is overt as they can limit its progression.
However, it is critical to employ other strategies, which could include the restoration of mitochondrial function by the stabilization of ATP synthesis, the blocking and inactivation of ROS (effective antioxidants) and probably the restoration of neurosteroid synthesis.

Corresponding medications remain to be found as they must present very specific characteristics. They must be able to cross the BBB, penetrate neuronal cells, exist in effective concentrations in mitochondria, all while being able to resist endoplasmic reticulum enzymes. It appears that some already marketed drugs used in other indications, like lithium, valproic acid, nicotine and selegiline, may be beneficial in some neurodegenerative diseases. This observation suggests that other 'old' drugs may be evaluated in these new indications, providing they have shown positive effects on neuron growth as, for instance, antidepressants. Although ambitious, these goals are nevertheless within reach.

\section{Acknowledgments}

It was impossible to quote all the numerous articles dealing with neurodegeneration. Therefore, we have selected the most informative reviews, specific studies dealing with new trends in therapy and some of our own studies in the field. The reader will find the corresponding original publications in the reviews. We want to thank Dr. Edith Albengres-Tillement for helpful reviewing, and Marie Piketty for her help in the bibliographical research. V.P. has been supported by a Canada Research Chair in Biochemical Pharmacology and L.L. by the Royal Victoria Hospital Centennial Fund. The Research Institute of the MUHC (McGill University Health Centre) is supported in part by a centre grant from the Fond de la Recherche en Santé du Québec.
References
1 Rosenberg RD: The molecular and genetic basis of AD: the end of the beginning. The 2000 Wartenberg lecture. Neurology 2000; 54:2045-2054

2 Games D, Adams D, Alessandrini R, Barbour R, Berthelette P, Blackwell C, Carr T, Clemens J, Donaldson T, Gillespie F, Guido T, Hagopian S, Johnson-Wood K, Khan K, Lee M, Leibowitz P, Lieberburg I, Little S, Masliah E, McConlogue L, Montoya-Zavala M, Mucke L, Paganini L, Penniman E, Power M, Schenk D, Seubert P, Snyder B, Soriano F, Tan H, Vitale J, Wadsworth S, Wolozin B, Zhao J: Alzheimer-type neuropathology in transgenic mice overexpressing V717F $\beta$ amyloid precursor protein. Nature 1995;373: 523-527.
- 3 Price DL, Tanzi RE, Porchelt DR, Sisodia SS: Alzheimer disease: genetic studies and transgenic models. Annu Rev Genet 1998;32:461493.

4 Lecanu L, Greeson J, Papadopoulos V: Betaamyloid and oxidative stress jointly induce neuronal death, amyloid deposits, gliosis, and memory impairment in the rat brain. Pharmacology 2006;76:19-33.

5 Prusiner SB: Novel proteinaceous infectious particles cause scrapie. Science 1982;216: 136-144.

6 Forman MS, Trojanowski JQ, Lee VM-Y: Neurodegenerative diseases: a decade of discoveries paves the way for therapeutic breakthroughs. Nat Med 2004;10:1055-1063. 
7 Skovronsky DM, Lee VM-Y, Trojanowski JQ: Neurodegenerative diseases: new concepts of pathogenesis and their therapeutic implications. Annu Rev Pathol 2006;1:151-170.

$\checkmark 8$ Dobson CM: Protein folding and misfolding. Nature 2003;406:884-890.

$\checkmark 9$ Bukau B, Horwich AL: The Hsp70 and Hsp60 chaperone machines. Cell 1998;92:351-366.

10 Hartl FU, Hayer-Hartl M: Molecular chaperones in the cytosol: from nascent chain to folded protein. Science 2002;295:1852-1858.

- 11 Kayed R, Head E, Thompson JL, McIntire TM, Milton SC, Cotma CW, Glabe CG: Common structure of soluble amyloid oligomers implies common mechanisms of pathogenesis. Science 2003;300:486-489.

-12 Giasson BI, Forman MS, Higuchi M, Golbe LL, Graves CL, Kotzbauer PT, Trojanowski JQ: Initiation and synergic fibrillization of tau and alpha-synuclein. Science 2003;300: 636-640.

13 Burn DJ: Parkinson's disease dementia: what's in a Lewy body? J Neural Transm Suppl 2006;70:361-365.

14 Takashima A: Preselenin 1 associates with glycogen synthetase kinase-3 and its substrate tau. Proc Natl Acad Sci USA 1998;95: 9637-9641.

-15 Leverenz JB, Umar I, Wang Q, Montine TJ, McMillan PJ, Tsuang DW, Jin J, Pan C, Shin J, Zhu D, Zhang J: Proteomic identification of novel proteins in cortical Lewy bodies. Brain Pathol 2007;17:139-145.

-16 Ghribi O, Golovko MY, Larsen B, Schrag M, Murphy EJ: Deposition of iron and beta-amyloid plaques is associated with cortical cellular damage in rabbit fed with long-term cholesterol-enriched diet. J Neurochem 2006;99:438-449.

17 Golbe LI: The genetics of Parkinson's disease: a reconsideration. Neurology 1990; 40(suppl 3):7-14.

-18 Zeviani M, Spinazzola A, Carelli V: Nuclear genes in mitochondrial disorders. Curr Opin Genet Dev 2003;13:262-270.

-19 Young-Pearse TL, Bai J, Chan R, Zheng JB, LoTurco JL, Selkoe DJ: A critical function for $\beta$-amyloid precursor protein in neuronal migration revealed by in utero RNA interference. J Neurosci 2007;27:14459-14469.

-20 Young-Pearse TL, Chen AC, Chang R, Zheng JB, Marquez C, Selkoe DJ: Secreted APP regulates the function of full-length APP in neurite outgrowth through interaction with integrin beta I. Neural Dev 2008;3:15.

-21 Schrenk-Siemens K, Perez-Alcala S, Richter J, Lacroix E, Rahuel J, Korte M, Müller U, Barde Y, Bibel M: Embryonic stem cell-derived neurons as a cellular system to study gene function: lack of amyloid precursor proteins APP and APLP2 leads to defective synaptic transmission. Stem Cells 2008;26: 2153-2163.
-22 Bai Y, Markham K, Chen F, Weerasekera R, Watts J, Home P, Wakutani Y, Bagshaw R, Mathews PM, Fraser PE, Westaway D, St George-Hyslop P, Schmitt-Ulms G: The in vivo brain interactome of the amyloid precursor protein. Mol Cell Proteomics 2008;7: 15-34.

23 Simons M, Keller P, de Strooper B, Beyreuther K, Dotti CG, Simons K: Cholesterol depletion inhibits the generation of $\beta$-amyloid in hippocampal neurons. Proc Natl Acad Sci USA 1998;95:6460-6464.

24 Bergmann C, Simons M, Jäkäiä P: Cholesterol depletion inhibits intracellular production of $A \beta_{40}$ and $A \beta_{42}$ Alzheimer's disease amyloid peptides (abstract 319). Soc Neurosci Abstracts 1999;25.

25 Yao ZX, Papadopoulos V: Function of $\beta$-amyloid in cholesterol transport: a lead to neurotoxicity. FASEB J 2002;16:1677-1679.

26 Yang LB, Lindholm K, Yan R, Citron M, Xia W, Yang XL, Beach T, Sue L, Wong P, Price D, Li R, Shen Y: Elevated beta-secretase expression and enzymatic activity detected in sporadic Alzheimer disease. Nat Med 2003, 9:3-4.

27 Li R, Lindholm K, Yang LB, Yue X, Citron M, Yan R, Beach T, Sue L, Sabbagh M, Cai H, Wong P, Price D, Shen Y: Amyloid beta peptide load is correlated with increased betasecretase activity in sporadic Alzheimer's disease patients. Proc Natl Acad Sci USA 2004;101:3632-3637.

28 Edbauer D, Winkler E, Regula JT, Pesold B, Steiner H, Haass C: Reconstitution of gamma-secretase activity. Nat Cell Biol 2003;5: 486-488.

29 Sato C, Morohashi Y, Tomita T, Iwatsubo T: Structure of the catalytic pore of gammasecretase probed by the accessibility of substituted cysteines. J Neurosci 2006;26:1208112088.

30 Yamasaki A, Eimer S, Okochi M, Smialowska A, Kaether C, Baumeister R, Haass R, Steiner H: The GxGD motif of presenilin contributes to catalytic function and substrate identification of gamma-secretase. J Neurosci 2006;26:3821-3828.

31 Drechsel DN, Hyman AA, Cobb MH, Kirschner MW: Modulation of the dynamic instability of tubulin assembly by the microtubule-associated protein tau. Mol Biol Cell 1992;3:1141-1154

32 Mazanetz MP, Fisher PM: Untangling tau hyperphosphorylation in drug design for neurodegenerative diseases. Nat Rev Drug Discov 2007;6:464-479.

-33 Nordlund A, Leinartaite L, Saraboji K, Aisenbrey C, Grobner G, Zetterstrom P, Danielsson J, Logan DT, Oliveberg M: Functional features cause misfolding of the ALS provoking enzyme SOD1. Proc Natl Acad Sci USA 2009;106:9667-9672.

-34 Neumann M: Molecular neuropathology of TDP-43 proteinopathies. Int J Mol Sci 2009; 10:232-246.
35 Peña F, Gutiérrez-Lerma A, Quiroz-Baez R, Arias C: The role of beta-amyloid protein in synaptic function: implications for Alzheimer's disease therapy. Curr Neuropharmacol 2006;4:149-163.

36 Zhu X, Lee HG, Perry G, Smith MA: Alzheimer disease, the two-hit hypothesis: an update. Biochim Biophys Acta 2007;1772: 494-502.

37 Olney JW, Ho OL: Brain damage in infant mice following oral intake of glutamate, aspartate or cystein. Nature 1970;227:609611.

38 Parihar MS, Brewer GJ: Mitoenergetic failure in Alzheimer disease. Am J Physiol Cell Physiol 2007;292:C8-C23.

-39 Farlow MR: NMDA receptor antagonists: a new therapeutic approach for Alzheimer's disease. Geriatrics 2004;59:22-27.

40 Coskun PE, Beal MF, Wallace DC: Alzheimer's brains harbor somatic mtDNA controlregion mutations that suppress mitochondrial transcription and replication. Proc Natl Acad Sci USA 2004;101:10726-10731.

41 Onyango IG, Khan SM: Oxidative stress, mitochondrial dysfunction, and stress signaling in Alzheimer disease. Curr Alzheimer Res 2006;3:339-349.

42 Zeviani M, Spinazzola A, Carelli V: Nuclear genes in mitochondrial disorders. Curr Opin Genet Dev 2003;13:262-270.

43 Augy T, Bonin-Guillaume S, Blin O: New therapeutic approaches in Alzheimer disease. Encephale 2006;32:641-649.

44 Pogacić V, Herrling P: List of drugs in development for neurodegenerative diseases: update June 2007. Neurodegener Dis 2007;4: 443-486.

45 Talley TT, Harel M, Hibbs RE, Radic Z, Tomizawa M, Casida JE, Taylor P: Atomic interactions of neonicotinoid agonists with AChBP: molecular recognition of the distinctive electronegative pharmacophore. Proc Natl Acad Sci USA 2008;105:76067611.

46 Lecanu L, Papadopoulos V: Cutting-edge patents in Alzheimer's disease drug discovery: anticipation of potential future treatments. Recent Pat CNS Drug Discov 2007;2: 113-123.

47 Lecanu L, Tillement L, Rammouz G, Tillement JP, Greeson J, Papadopoulos V: Caprospinol: moving from a neuroactive steroid to a neurotropic drug. Expert Opin Investig Drugs 2009; 18:265-276.

-48 Creeley CE, Wozniak DF, Nardi A, Farber NB, Olney JW: Donepezil markedly potentiates memantine neurotoxicity in the adult rat brain. Neurobiol Aging 2008;29:153167.

49 Frémont L: Biological effects of resveratrol. Life Sci 2000;66:663-673. 
-50 Orgogozo JM, Dartigues JF, Lafont S, Letenneur L, Commenges D, Salamon R, Renaud $\mathrm{S}$, Breteler MB: Wine consumption and dementia in the elderly: a community prospective study in the Bordeaux area. Rev Neurol (Paris) 1997;153:185-192.

-51 Tillement J-P: In vitro protection of cerebral mitochondria function by E-resveratrol in anoxia followed by re-oxygenation. Bull Acad Natl Med 2001;185:1429-1445.

52 Mazza M, Capuano A, Bria P, Mazza S: Ginkgo biloba and donepezil: a comparison in the treatment of Alzheimer's dementia in a randomized placebo-controlled double-blind study. Eur J Neurol 2006;13:981-985.

- 53 Vellass B, Andrieu S, Ousset PJ, Ouzid M, Mathiex-Fortunet H, Guid Age Study Group: The GuidAge Study - methodological issues: a 5-year double-blind randomized trial of the efficacy of EGb761 for prevention of Alzheimer disease in patients over 70 with a memory complaint. Neurology 2006;67:S6S11.

54 Schapira AH, Bezard E, Brotchie J, Calon F, Collingridge GL, Ferger B, Hengerer B, Hirsch E, Jenner P, Le Novère N, Obeso JA, Schwarzschild MA, Spampinato U, Davidai G: Novel pharmacological targets for the treatment of Parkinson's disease. Nat Rev Drug Discov 2006;5:845-854.

-55 Fornai F, Longone P, Cafaro L, Kastsiuchenka O, Ferruci M, Manca ML, Lazzeri G, Spalloni A, Bellio N, Lenzi P, Modugno N, Siciliano G, Isidoro C, Murri L, Ruggieri S, Paparelli A: Lithium delays progression of amyotrophic lateral sclerosis. Proc Natl Acad Sci USA 2008; 105:2052-2057.

-56 Carter CJ: Convergence of genes implicated in Alzheimer's disease on the cerebral cholesterol shuttle: APP, cholesterol, lipoproteins and atherosclerosis. Neurochem Int 2007;50:12-38.

-57 Wolozin B, Kellman W, Rousseau P, Celesia GG, Siegel G: Decreased prevalence of Alzheimer disease associated with 3-hydroxy3-methylglutaryl-coenzyme A reductase inhibitors. Arch Neurol 2000;57:1439-1443.

- 58 Shepherd J, Blauw GJ, Murphy MB, Bollen EL, Buckley BM, Cobbe SM, Ford I, Norrie J, Packard CJ, Perry IJ, Stott DJ, Sweeney BJ, Twome C, Westendorp RG, PROPER study group: Pravastatin in elderly individuals at risk of vascular disease (PROSPER): a randomised controlled trial. PROspective Study of Pravastatin in the Elderly at Risk. Lancet 2002;360:1623-1630.

-59 Simons M, Keller P, de Strooper B, Beyreuther K, Dotti CG, Simons K: Cholesterol depletion inhibits the generation of [beta]-amyloid in hippocampal neurons. Proc Natl Acad Sci USA 1998;95:6460-6464.

-60 Papadopoulos V, Lecanu L, Brown RC, Han Z, Yao ZK: Peripheral-type benzodiazepine receptor in neurosteroid biosynthesis, neuropathology and neurological disorders. Neuroscience 2006;138:749-756.
61 Lacor P, Gandolfo P, Tonon MC, Brault E, Dalibert I, Schumacher M, Benavides J, Ferzaz B: Regulation of the expression of peripheral benzodiazepine receptors and their endogenous ligands during rat sciatic nerve degeneration and regeneration: a role for PBR in neurosteroidogenesis. Brain Res 1999;815:70-80.

62 Lacapère JJ, Papadopoulos V: Peripheraltype benzodiazepine receptor: structure and function of a cholesterol-binding protein in steroid and bile acid biosynthesis. Steroids 2003;68:569-585.

63 Wright G, Reichenberger V: The effects of superoxide and the peripheral benzodiazepine receptor ligands on the mitochondrial processing of manganese-dependent superoxide dismutase. Exp Cell Res 1999;246: 443-450.

64 Hauet T, Yao ZX, Bose HS, Wall CT, Han Z, Hales DB, Miller WL, Culty M, Papadopoulos V: Peripheral-type benzodiazepine receptor-mediated action of steroidogenic acute regulatory protein on cholesterol entry into Leydig cell mitochondria. Mol Endocrinol 2005; 19:540-554.

65 Xie C, Lund EG, Turley SD, Russel DW, Dietschy JM: Quantification of two pathways for cholesterol excretion from the brain in normal mice with neurodegeneration. J Lipid Res 2003;44:1780-1789.

66 Barbaccia ML: Neurosteroidogenesis: relevance to neurosteroid actions in brain and modulation by psychotropic drugs. Crit Rev Neurobiol 2004; 18:67-74.

67 Puglielli L, Konopka G, Pack-Chung E, Ingano LA, Berezovska O, Hyman BT, Chang TY, Tanzi RE, Kovacs DM: Acyl-coenzyme A:cholesterol acyltransferase modulates the generation of the amyloid $\beta$-peptide. Nat Cell Biol 2001;3:905-912.

68 LütjohannD, Papassotiropoulos A,Björkhem I, Locatelli S, Bagli M, Gehring RD, Schlegel U, Jessen F, Rao ML, von Bergmann K, Heun R: Plasma 24S-hydroxycholesterol (cerebrosterol) is increased in Alzheimer and vascular demented patients. J Lipid Res 2000;41: 195-198.

69 Papassotiropoulos A, Lütjohann D, Bagli M, Locatelli S, Jessen F, Buschfort R, Ptok U, Björkhem I, von Bergmann K, Heun R: 24Shydroxycholesterol in cerebrospinal fluid is elevated in early stages of dementia. J Psychiatr Res 2002;36:27-32.

-70 Delavoie F, Li H, Hardwick M, Robert JC, Giatzakis C, Péranzi G, Yao ZX, Maccario J, Lacapère JJ, Papadopoulos V: In vivo and in vitro peripheral-type benzodiazepine receptor polymerisation: functional significance in drug ligand and cholesterol binding. Biochemistry 2003;42:4506-4519.

71 Yao ZX, Brown RC, Teper G, Greeson J, Papadopoulos V: 22R-hydroxycholesterol protects neuronal cells from $\beta$-amyloid-induced cytotoxicity by binding to $\beta$-amyloid peptide. J Neurochem 2002;83:1-10.
72 Lecanu L, Yao W, Teper GL, Greeson J, Papadopoulos V: Identification of naturally occurring spirostenols preventing beta-amyloid-induced neurotoxicity. Steroids 2004; 69:1-16.

73 Tillement L, Lecanu L, Yao W, et al: The spirostenol (22R,25R)-20 $\alpha$-spirost-5-en$3 \beta$-yl hexanoate blocks mitochondrial uptake of $A \beta$ in neuronal cells and prevents $A \beta$-induced impairment of mitochondrial function. Steroids 2006;71:725-735.

74 Puglielli L, Tanzi RE, Kovacs DM: Alzheimer's disease: the cholesterol connection. Nat Neurosci 2003;6:345-351.

75 Saudou F, Finkbeiner S, Devys D, Greenberg ME: Huntingtin acts in the nucleus to induce apoptosis but death does not correlate with the formation of intranuclear inclusions. Cell 1998;95:55-66.

76 Valenza M, Cattaneo E: Cholesterol dysfunction in neurodegenerative diseases: is Huntington's disease in the list? Prog Neurobiol 2006;80:165-176.

77 Onuki Y, Morishita M, Chiba Y, Tokiwa S, Takayama K: Docosahexaenoic acid and eicosapentaenoic acid induce changes in the physical properties of a lipid bilayer model membrane. Chem Pharm Bull (Tokyo) 2006; 54:68-71.

78 Bosco DA, Fowler DM, Zhang Q, Nieva J, Powers ET, Wentworth P Jr, Lerner RA, Kelly JM: Elevated levels of oxidized cholesterol metabolites in Lewy body disease brains accelerate alpha-synuclein fibrillization. Nat Chem Biol 2006;2:249-253.

79 Prabhakara JPR, Feist G, Thomasson S, Thompson A, Schommer E, Ghribi O: Differential effects of 24-hydroxycholesterol and 27-hydroxycholesterol on tyrosine hydroxylase and $\alpha$-synuclein in human neuroblastoma SH-SY5Y cells. J Neurochem 2008; 107:1722-1729.

80 Bar-On P, Crews L, Koob AO, Mizuno H, Adame A, Spencer B, Masliah E: Statins reduce neuronal alpha-synuclein aggregation in in vitro models of Parkinson's disease. J Neurochem 2008;105:1656-1667.

-81 Huang X, Chen H, Miller MC, Mailman RB, Woodard JL, Chen PC, Xiang D, Murrow RW, Wang YZ, Poole C: Lower low-density lipoprotein cholesterol levels are associated with Parkinson's disease. Mov Disord 2007; 22:377-381.

- 82 Biomel M, Grigoriadis N, Loourbopoulos A, Touloumi O, Rosenmann D, Abramsky O, Rosenmann H: Statins reduce the neurofibrillary tangle burden in a mouse model of tauopathy. J Neuropathol Exp Neurol 2009; 68:314-325

83 Tsai SJ: Statins may act through increasing tissue plasminogen activator/plasmin activity to lower risk of Alzheimer's disease. CNS Spectr 2009; 14:234-235. 
84 Onyango IG, Khan SM: Oxidative stress, mitochondrial dysfunction, and stress signaling in Alzheimer disease. Curr Alzheimer Res 2006;3:339-349.

>85 Parihar MS, Brewer GJ: Mitoenergetic failure in Alzheimer disease. Am J Physiol Cell Physiol 2007;292:C8-C23.

-86 Dawson TM, Dawson VL: Molecular pathways of neurodegeneration in Parkinson's disease. Science 2003;302:819-822.

$>87$ Cormier A, Morin C, Zini R, Tillement J-P: Nicotine protects rat brain mitochondria against experimental injuries. Neuropharmacology 2003;44:642-652.

-88 Morin D, Hauet T, Spedding M, Tillement JP: Mitochondria as target for anti-ischemic drugs. Adv Drug Deliv Rev 2001;49:151174.
89 Papadopoulos V, Liu J, Culty M: Is there a mitochondrial signaling complex facilitating cholesterol import? Mol Cell Endocrinol 2007;265-266:59-64.

90 Heneka MT, Landreth GE, Hull M: Drug insight: effects mediated by peroxisome proliferator-activated receptor- $\gamma$ in CNS disorders. Nat Clin Pract 2007;3:496-504.

91 Heneka MT, Sastre M, Dumitrescu-Ozimek L, Hanke A, Dewachter I, Kuiperi C, O'Banion K, Klockgether T, van Leuven F, Landreth GE: Acute treatment with the PPAR- $\gamma$ agonist pioglitazone and ibuprofen reduces glial inflammation and $A \beta_{1-42}$ levels in APPV717I transgenic mice. Brain 2005; 128:1442-1453.
92 Watson GS, Cholerton BA, Reger MA, Baker LD, Plymate SR, Asthana S, Fishel MA, Kulstad JJ, Green PS, Cook DG, Kahn SE, Keeling ML, Craft S: Preserved cognition in patients with early Alzheimer disease and amnestic mild cognitive impairment during treatment with rosiglitazone: a preliminary study. Am J Geriatr Psychiatry 2005;13:950958.

93 Risner ME, Saunders AM, Altman JF, Ormandy GC, Craft S, Foley IM, Zvartau-Hind ME, Hosford DA, Roses AD, Rosiglitazone in Alzheimer's Disease Study Group: Efficacy of rosiglitazone in a genetically defined population with mild-to-moderate Alzheimer's disease. Pharmacogenomics J 2006;6: 246-254. 